\title{
П.В. Тепляшин
}

\section{ПРИБАЛТИЙСКИЙ ТИП ЕВРОПЕЙСКИХ ПЕНИТЕНЦИАРНЫХ СИСТЕМ}

\begin{abstract}
Обосновывается, что для прибалтийского пенитенциарного типа характерна реализация преимущественно западноевропейских образцов обращения с заключенными, что предполагает в основном тюремнопокамерное размещение осужденных с элементами прогрессивной системы. Показано участие стран в международных проектах, внедрение индивидуальных программ отбывания наказания и использование токсикологического тестирования осужденных. Обращается внимание на недостатки в организации деятельности тюрем.
\end{abstract}

Ключевые слова: Департамент пенитенциарных учреждений Литвы, модель размещеения осужденных, проект «Норд-Балт», Таллиннская тюрьма.

В Концепции развития уголовно-исполнительной системы Российской Федерации до 2020 г. (в редакции от 23 сентября 2015 г.) говорится о совершенствовании деятельности учреждений и органов, исполняющих наказания, с учетом международных стандартов и потребностей общественного развития [1]. Реализация таких стандартов отражается в практической стороне деятельности органов управления и функционирования исправительных учреждений, процедурах обращения с осужденными и опыте правового регулирования их исправления и реабилитации в зарубежных странах. Соответственно обратиться к научно обоснованным перспективам модернизации отечественного законодательства в сфере исполнения уголовных наказаний и по новому взглянуть на правоприменительную практику, сопутствующую реформированию уголовно-исполнительной системы, позволяет исследование европейских пенитенциарных систем.

Научный интерес представляет прибалтийский тип европейских пенитенциарных систем (Эстония, Латвия, Литва), который обладает определенными особенностями, заслуживающими самостоятельного рассмотрения. Так, в условиях распространенного мнения о том, что эталонной моделью обращения с осужденными выступают пенитенциарные системы стран Западной Европы, государства, представляющие прибалтийский тип, являются своеобразной площадкой верификации активно внедряемых западных образцов в сфере исполнения уголовных наказаний. Более того, как и Россия, прибалтийские государства осуществляют активные пенитенциарные преобразования, но вместе с тем переживают дефицит их экономического сопровождения.

Прибалтийский пенитенциарный тип (Эстония, Латвия, Литва) основывается на тесном географическом и историческом соседстве трех государств, в настоящее время заинтересованных в восприятии как можно в большей степени идеалов западноевропейского права для модернизации публичного права, на которое определенное время оказывалось воздействие со стороны социалистической правовой системы.
Органы управления пенитенциарными учреждениями в государствах прибалтийского пенитенциарного типа подведомственны соответствующим министерствам юстиции.

Тюремная администрация Латвии осуществляет управление исправительными учреждениями (всего их 12), подразделяющимися в зависимости от степени обеспечения безопасности персонала и общества на три типа: закрытого (4 учреждения), полуоткрытого (к данному виду можно также отнести исправительную колонию для несовершеннолетних юношей) и открытого (4). В Латвии несовершеннолетние мужского пола отбывают наказание в исправительном учреждении для несовершеннолетних в Цесисе, несовершеннолетние женщины в отдельном блоке тюрьме Ильгюциемс. При этом значимость для тюремного ведомства задач по ресоциализации и социальной адаптации осужденных объясняет подчиненность ему также Государственной службы пробации, созданной в 2003 г. Не случайно специалистами отмечается, что «появление института пробации в Латвии продолжает реформу уголовно-исполнительной системы, начавшуюся с тюремной реформы, отмены смертной казни» [2, с. 132].

Департаменту пенитенциарных учреждений Литвы подчиняется 9 учреждений, включая 4 исправительных дома, 1 исправительный дом - следственный изолятор, 2 следственных изолятора, 1 тюрьму, 1 тюремную больницу, а также учебный центр для сотрудников и 4 службы пробации [3].

Тюремная служба Эстонии для государства с небольшим населением имеет достаточно разветвленную систему, которая находятся под непосредственным контролем со стороны Канцелярии Канцлера юстиции [4]. Таллиннская и Тартуская тюрьмы относятся к исправительным учреждениям закрытого типа, в первой из которых находится медицинское исправительное учреждение, мужская закрытая тюрьма Вильянди, которая имеет открытое отделение для содержания несовершеннолетних юношей, учреждение Харку и Муру представляет объединение закрытой и открытой тюрем, включая отдельные блоки для содержания несовершеннолетних девушек, престарелых осужденных и лиц женского 
пола, проходящих реабилитацию после лечения от наркотической зависимости. Виру - объединение закрытой и открытой тюрем, арестного дома и следственного изолятора [5].

Среди основных правовых актов, регламентирующих сферу исполнения уголовных наказаний в Латвии, следует отметить Конституцию 1998 г., Уголовный кодекс 1998 г., Кодекс об исполнении наказаний 1998 г., Тюремный закон об администрации 2002 г., Тюремные административные правила 2005 г., Тюремные внутренние правила 2006 г. В Литве - это Конституция 1992 г., Уголовный кодекс 2000 г., Закон о судах 1994 г., Уголовнопроцессуальный кодекс 2002 г., Правила для пенитенциарных учреждений, утвержденные Министерством юстиции в 2000 г., Служебный устав Департамента пенитенциарных учреждений 2000 г. С 2000 г. принимаются Уставы тюрем, закрепляющие основные задачи пенитенциарных учреждений, включая подготовку осужденных к освобождению и интеграции в общество. Также следует обратить внимание на Санитарные правила для помещений, содержания и охраны здоровья в местах содержания под стражей в Республике Литва, изначально утвержденные Министерством здравоохранения в 1999 г., на основании которых были разработаны стандарты по минимальной площади для каждого заключенного, в том числе отбывающих наказание, и закреплены гарантии на отдых, ежедневную прогулку на открытом воздухе продолжительностью не менее часа (независимо от поведения заключенного), предусмотрена возможность готовить самостоятельно пищу, более частое получение передач и увеличение их разрешенного веса. Среди основных эстонских источников следует отметить Уголовный кодекс 2001 г. (также официально именуемый Пенитенциарным кодексом), Уголовно-процессуальный кодекс 2003 г., Кодекс этики тюремных служащих 2008 г., Закон от 19 ноября 1997 г. № 87 «О пенитенциарном регистре», Закон от 14 июня 2000 г. № 58 «О тюремном заключении», а также постановление Министерства юстиции от 30 ноября 2000 г. № 72 «О правилах внутреннего распорядка тюрьмы».

На основе информации, полученной на официальном сайте Международного центра тюремных исследований [6], можно сделать вывод, что прибалтийскому типу (приводятся средние по трем странам величины) свойственен один из самых высоких среди всех типов европейских пенитенциарных систем коэффициент заключенных (274), что при ниже нормативной наполняемости исправительных учреждений $(90,8$ \%) свидетельствует о значительных площадях и количестве исправительных учреждений (включая тюремные больницы и учреждения предварительного заключения) Латвии, Литвы и Эстонии (по 11, 15 и 4 соответственно в каждой стране). При этом следует учитывать, что в этих странах за последние десятилетия наблюдается снижение общего числа заключенных. Например, в Латвии, Литве и Эстонии в 1992 г. содержалось
8340, 9175 и 4778 заключенных соответственно, в 1995 г. - 9457, 12782 и 4401, в 1998 г. - 10070, 13628 и 4769 , в 2004 г. - 8179, 8063 и 4577, в 2007 г. 6548,8079 и 4310 , в 2010 г. $-7055,8655$ и 3555 , по состоянию на апрель 2014 г. в Латвии - содержалось уже только 5280 заключенных, по состоянию на сентябрь 2013 г. в Литве - 9509, по состоянию на сентябрь 2014 г. в Эстонии 3075 лиц находилось в тюремном заключении. Эти статистические данные говорят о том, что для прибалтийского типа пенитенциарной системы свойственно, с одной стороны, традиционно высокий уровень «тюремного населения», с другой - положительная динамика (при определенной «волнообразности») в части постепенного снижения фактического количества осужденных. Также следует указать на ощутимый удельный вес заключенных, являющихся гражданами иностранных государств, в общей массе осужденных (13,5 \%).

Данный тип по существу имеет переходный характер, поскольку он характеризуется попыткой отхода от советской модели пенитенциарной системы к реализации образцов преимущественно западноевропейской модели. Например, ярко это прослеживается в рамках реализованного в период с 1997 по 2004 г. проекта «Норд-Балт» - своеобразное содружество между отдельными исправительными учреждениями Швеции, Норвегии и Латвии. По мнению О.А. Ивановой, позитивная роль проекта состоит в том, что если «десять лет назад абсолютное большинство осужденных проводило время в праздности, то сегодня $30 \%$ из них работают или осваивают профессию. Это тоже, конечно, малый показатель, но по сравнению с тем, что было, прогресс налицо. Самый большой процент работающих и осваивающих профессии - в Ильгюциемской женской тюрьме (90\%). Сейчас трудоустройством осужденных занимается специально созданный в Управлении местами заключения отдел занятости, который договаривается с частными фирмами об обучении заключенных разным профессиям» [7, с. 61].

Наблюдается достаточно активное сотрудничество с пенитенциарными органами управления европейских стран и участие в различных международных проектах по развитию прогрессивных форм и методов обращения с осужденными. Так, совместно с Европейским институтом по предупреждению преступности и борьбе с ней (The European Institute for Crime Prevention and Control) Литва, Латвия и Эстония принимает участие в проекте «DAPHNE Strong», который координируется Научно-исследовательским институтом медицинской ассоциации Германии и финансируется программой Европейской комиссии DAPHNE III [8]. Причем нельзя не заметить, что начиная с 2011 г. первыми активными участниками проекта выступили такие государства, как Финляндия, Швеция, Норвегия и Дания [9]. Целью проекта выступает оптимизация существующих европейских программ и практик обращения с заключенными женщинами, испытавшими различные формы физического и сексуального насилия [10]. 
Основными зарубежными партнерами по линии оптимизации практики обращения с осужденными выступают Финляндия, Швеция, Норвегия, Дания, Великобритания, Германия и Грузия. В частности, общение эстонских пенитенциарных специалистов с коллегами тюремной системы Великобритании осуществляется в рамках программы Европейского Союза EQUAL развития международного партнерства «New Horizons» и при посредничестве Целевого учреждения по предупреждению преступности (Kuriteoennetuse Sihtasutus), Германии - посредством прохождения непродолжительного обучения в образовательных заведениях, занимающихся обучением тюремных работников, Швеции - в рамках проекта «Представитель для контактов», что привело к значительным корректировкам штатной структуры и функций персонала Таллиннской тюрьмы, Норвегии - по реализации применяемой в норвежских исправительных учреждениях с 2003 г. мультимодальной мотивационной программы для женщин-заключенных [11, p. 298] (VINN - от норвежского слова «vin» - выиграть), которая представляет налаживание сотрудничества между сотрудниками исправительного учреждения и осужденными женщинами с целью формирования последними личной автономии, сильных качеств личности, извлечения внутренних ресурсов за счет увеличения объема персональной осведомленности и расширения стратегии выживания [12, р. 81-96]. Кроме того, Министерство юстиции Эстонии принимало участие в двухгодичной программе TACIS, проходившей под управлением Европейской комиссии, в рамках которой проводятся консультации и обучение по организации профессионального обучения заключенных, по программам возвращения в общество, особенностями процесса досрочного освобождения, а также с принципами обеспечения надзора и безопасности в местах лишения свободы.

Специалистами в области пенитенциарной компаративистики не без основания делается вывод о том, что международные проекты позволили Эстонии «приблизить деятельность пенитенциарных органов к международным стандартам, реформировать систему пенитенциарных органов, улучшить статус лиц, отбывающих наказание» [13, с. 32].

Условия содержания заключенных во многих исправительных учреждениях строятся на тюремнопокамерной модели размещения осужденных с элементами прогрессивной системы (высокий, средний и низкий уровни), при которой исправительное воздействие предусматривает допуск осужденного к различным фазам воздействия (используются элементы французского типа пенитенциарной системы). Также допускается размещение осужденных по четыре в камере с попытками организации исправительного воздействия посредством использования труда (как оплачиваемого, так и неоплачиваемого) заключенных в мастерских и мини-цехах (используются элементы германского типа пенитенциарной системы).
В некоторых полуоткрытых тюрьмах, в первую очередь в Латвии, осужденные размещаются в общежитиях по 30-60 человек, что, как отмечается в специальных исследованиях, является наследием советских времен [14]. Однако тяготение к западной модели режима демонстрирует повышение требований к обеспечению безопасности исправительных учреждений и постепенный переход к покамерному принципу размещения осужденных. Соответственно закономерной является модель, на которую указывает такой видный отечественный ученый-пенитенциарист, как В.А. Уткин, согласно которой элементы режима уже не имеют четкой детализации в правовых актах, он устанавливается и меняется во внесудебном порядке, но в условиях судебного контроля, критериями строгости режима выступают личность осужденного и динамика её изменения в процессе отбывания наказания [15, с. 53-54].

Однако в следственных изоляторах и закрытых исправительных учреждениях (в том числе в Рижской центральной тюрьме) практикуется камерное содержание осужденных с ежедневными прогулками около 1 часа. В полуоткрытых тюрьмах осужденным предоставляется возможность посещения в рамках исправительного учреждения школы, профессионального училища, ремесленных цехов, комнат психологической разгрузки и работы с воспитателями, досуговые и спортивные площадки, мест приготовления и приема пищи, санитарно-прачечных и иных помещений. В открытых тюрьмах при отсутствии дисциплинарных взысканий предусмотрены длительные свидания, упрощенный пропускной режим, кратковременные выходы для посещения социальных служб, допускается раз в месяц покидать исправительное учреждение на несколько дней в целях установления, закрепления или сохранения социально-полезных связей [16].

Достаточно активно внедряются индивидуальные программы отбывания наказания. Например, согласно ч. 1 ст. 16 Закона Эстонии от 14 июня 2000 г. № 58 «О тюремном заключении», в отношении осужденного, срок отбывания тюремного заключения которого превышает один год, составляется индивидуальная программа исполнения наказания, в которой предусматривается: 1) размещение заключенного в тюрьме; 2) перевод заключенного в тюрьму открытого типа или другую тюрьму закрытого типа; 3) трудоспособность и профессиональные навыки заключенного; 4) необходимость в получении заключенным общего образования или профессионального образования либо трудового обучения; 5) применяемые к заключенному льготы; 6) меры, необходимые для подготовки заключенного к освобождению; 7) иные меры, необходимые для достижения целей исполнения наказания в виде лишения свободы. В ч. 2 указывается, что с заключенным обсуждается составленная в отношении него индивидуальная программа исполнения наказания.

Рассматриваемый тип европейских пенитенциарных систем характеризуется широкой практикой 
использования токсикологического тестирования (при поступлении и затем, как правило, дважды в течение года) направляемых в исправительные учреждения осужденных, ведение электронных баз данных, специально предназначенных для учета заболеваний (в основном, иммунодефицита, гепатита В и С, наркомании, туберкулеза) лиц, отбывающих наказания, результатов проводимого лечения и реабилитации. Например, в тюрьмах Эстонии в конце 2012 г. 15,6 \% всех заключенных имели диагноз ВИЧ-инфицирования, а 28,5 \% - больные наркоманией (50\% из которых использовали опиаты). Однако именно в этой стране наблюдаются установления диагноза отрицательного диагноза ВИЧинфицирования при освобождении в 97 \% (по состоянию на март 2013 г.) [17, p. 33]. При этом важно заметить, что указанное государство находится на третьем месте среди европейских государств (после России и Украины) по уровню ВИЧ-инфицирования населения (27,3 на 100 тыс.) [18], поэтому, на фоне выводов специалистов о сложной обстановке с охраной здоровья лиц, содержащихся в местах изоляции от общества, в целом по Европе [19, р. 5-8], действия администрации Тюремного управления Эстонии наглядно отражают их усилия по лечению и реабилитации больных осужденных.

Обращает внимание достаточно детальная правовая регламентация и энергичная работа пенитенциарных учреждений по воспитательной и ресоциализирующей работе с несовершеннолетними осужденными. Так, согласно ч. 1 ст. 62 Кодекса об исполнении наказаний Латвии, работа с осужденными в местах лишения свободы должна осуществляться в рамках ресоциализации и в целях обеспечения того, чтобы молодые люди могли приобретать общее образование. Причем в соответствии с ч. 7 ст. 50.7 отмеченного Кодекса процесс образования в отношении несовершеннолетних в исправительных учреждениях должен быть приближен к требованиям общеобразовательных учреждений, что необходимо регулировать инструкцией, согласованной с министром образования и науки и утвержденной министром юстиции. Статья 50.18 указанного правового акта Латвии (в редакции от 1 февраля 2015 г.) регламентирует процедуру принятия решения аттестационной комиссии исправительного учреждения по смягчению режима исполнения наказания в целях ресоциализации несовершеннолетнего осужденного, а также по рассмотрению вопроса об его оставлении в воспитательном учреждении по достижении 18-летнего возраста с целью закончить учебный год либо даже до окончания всего срока назначенного наказания, но не более чем до достижения им 25-летнего возраста, с целью получения общего образования.

Однако проблемы общения разновозрастных осужденных потребовали и достаточно твердых мер дисциплинарного воздействия на осужденных, отбывающих наказание в воспитательных учреждениях. Например, ст. 70 Кодекса об исполнении наказа- ний Латвии в качестве одного из дисциплинарных взысканий предусматривает водворение несовершеннолетнего осужденного за нарушение порядка отбывания наказания в дисциплинарный изолятор, а за грубое и систематическое нарушение дисциплины в одиночную камеру на срок до 10 суток. В связи с этим Витолдс Захарс (руководил Латвийской тюремной администрацией с 1997 по 2002 г.) и Марис Стиврениекс справедливо полагают, что применение такого дисциплинарного взыскания «может иметь непоправимое психологическое воздействие и травмировать психику несовершеннолетнего осужденного» [20, p. 226].

Появление и строительство частных тюрем и даже следственных изоляторов (особенно в Латвии) во всех трех странах обусловлено отчасти формированием доверия общественности к данному институту, а также предопределено проблемами государственного финансирования пенитенциарных учреждений и их решением посредством государственно-частного экономического партнерства в этой сфере. Однако задачи по охране в данных исправительных учреждениях остаются возложенными на государство.

В отчетах представителей Европейского комитета по предупреждению пыток и бесчеловечного или унижающего достоинство обращения или наказания (СРТ), посетивших с визитом государства, пенитенциарные системы которых охватываются прибалтийским типом, обнаруживается ряд проблем, связанных с исполнением тюремного заключения. Так, отмечены проблемы, связанные с трудоустройством осужденных в исправительных учреждениях (например, в Таллиннской тюрьме из 664 осужденных имеют возможность работать только 138 заключенных), переполненностью тюрем, ограниченным доступом к естественному свету и слабой вентиляцией помещений, словесными оскорблениями и чрезмерным применением силы в отношении осужденных со стороны персонала [21]. В Национальном докладе Государственного департамента США по правам человека 2013 г. по итогам визита в Эстонию указывается на слабую доступность заключенных к медицинской помощи и возможность телефонных разговоров с родственниками, проблемы с пожарной безопасностью, а также на периодические факты самоубийств осужденных и лиц, содержащихся под стражей [22].

По результатам посещения СРТ с 12 по 17 сентября 2013 г. Латвии в отчете отмечается на необходимость увеличения в некоторых тюрьмах размеров помещений, где осужденные принимают пищу, смотрят телевизор, общаются, а также на минимизацию применения наручников, поскольку их использование лишь провоцирует заключенных на дальнейшее нарушение дисциплины. Отмечена недостаточность применения мер безопасности внутри тюремного периметра (указанная проблема была затронута в связи с участившимися массовыми беспорядками в закрытых тюрьмах Латвии, случаем побега в одной из тюрем в 2013 г.), нехватка целенаправ- 
ленных исправительных мероприятий (работа, образование) в тюрьмах закрытого, а также частично закрытого (полуоткрытого) типа. Комитет предписывает обеспечивать осужденным условия для физического развития, в частности установить какие-либо тренажеры и турники на территории, где осужденные находятся на прогулке. Вызвал возмущение тот факт, что вследствие нехватки медицинского персонала администрация тюрем зачастую использует самих осужденных в качестве медбратьев [23]. На ситуацию с плохим медицинским обслуживанием, слабой инфраструктурой, недостаточным жизненным пространством (некоторые заключенные проживали на площади в 27 квадратных футов или меньше, тогда как положено не менее 43 квадратных футов) и случаи суицидов, по которым затягивается расследование, указывается и в Национальном докладе Государственного департамента США по правам человека 2014 г. по итогам визита в Латвию [24].

Также одной из негативных тенденций в тюрьмах Латвии выступает наличие феномена криминальной субкультуры. Причем данное явление достаточно сильно распространено в учреждении для несовершеннолетних лиц мужского пола. Витолдс Захарс и Марис Стиврениекс отмечают, что последствием такой ситуации выступает более высокий рецидив преступлений несовершеннолетних лиц, отбывших тюремное заключение $(37,5$ \%), тогда как у освободившихся взрослых осужденных рецидив составляет $20,6 \%$ [20, с. 223].

Принять меры по устранению чрезмерного применения силы в тюрьмах, улучшению материальных условий содержания под стражей (в докладе приводятся такие недостатки, как ограниченность естественного освещения, отсутствие перегородок между туалетами в камерах, грязные матрасы и одеяла и т.д.), по сокращению перенаселенности мест содержания под стражей и систематической сегрегации приговоренных к пожизненному заключению обязал Литву СРТ по итогам посещения государства в период с 27 ноября по 4 декабря 2012 г. Непосредственно в отношении посещенных тюрем, делегация Комитета получила ряд достоверных сообщений о намеренном жестоком физическом обращении и чрезмерном применении силы (в основном, битьё руками, ногами и дубинками), допускаемом сотрудниками тюрем в Алитусе и Шяуляе. В некоторых случаях делегация собрала медицинские свидетельства, подтверждающие соответствие этих утверждений действительности. Кроме того, отмечен высокий уровень насилия среди заключенных тюрьмы в Алитусе, что отчасти связано с тем, что лишь небольшое число надзирателей бывают в помещениях, где живут заключенные, в течение дня и еще меньше - в ночное время и в выходные дни. Обращается внимание на бедность материальных условий содержания, перенаселенность большинства посещенных учреждений, а также нехватку медицинских работников и ресурсов в тюрьмах в Алитусе и Лукишкесе [25]. Отмечается переполненность большинства исправительных учреждений и их несоответствие международным стандартам в области обращения с осужденными в Национальном докладе Государственного департамента США по правам человека 2013 г. по итогам визита в Литву [26].

Представленная краткая характеристика прибалтийского типа европейских пенитенциарных систем показывает его определенные особенности, вызванные в первую очередь одним из самых высоких среди всех типов европейских пенитенциарных систем коэффициентом заключенных, ощутимым удельным весом заключенных, являющихся гражданами иностранных государств, в общей массе осужденных. Рассмотренному типу свойственен отход от советской модели содержания осужденных и реализация преимущественно западноевропейских образцов обращения с заключенными, поэтому условия содержания заключенных во многих исправительных учреждениях предполагают тюремно-покамерное размещение осужденных с элементами прогрессивной системы. Повышаются требования к режиму как средству обеспечения безопасности исправительного учреждения, его элементы уже не имеют четкой детализации в правовых актах, он устанавливается и меняется во внесудебном порядке. Имеет место достаточно детальная правовая регламентация и энергичная работа пенитенциарных учреждений по воспитательной и ресоциализирующей работе с несовершеннолетними осужденными.

Наблюдается достаточно активное сотрудничество с органами управления исправительными учреждениями европейских стран и участие в различных международных проектах («DAPHNE Strong», «New Horizons», VINN, TACIS и др.), а также внедрение индивидуальных программ отбывания наказания и использование токсикологического тестирования осужденных.

Появление и строительство частных тюрем обусловлено отчасти формированием доверия общественности к данному институту, а также предопределено возможностью решения проблем государственного финансирования пенитенциарных учреждений посредством государственно-частного экономического партнерства в этой сфере.

Однако имеются замечания и рекомендации со стороны контролирующих органов Совета Европы и иных правозащитных организаций относительно функционирования исправительных учреждений.

Таким образом, в условиях дефицита приемлемых для российской правовой действительности зарубежных моделей обращения с осужденными и критического отношения к результатам компаративистской пенологии анализ прибалтийского пенитенциарного типа позволяет пристальнее присмотреться к перспективам реформы отечественной уголовно-исполнительной системы, получившей с сентября 2015 г. новый концепт, и обуславливает закономерный научный интерес к типологическому компаративистскому анализу всей европейской пенитенциарной карты. 


\section{ЛИТЕРАТУРА}

1. Распоряжение Правительства Российской Федерации № 1772-р от 14 октября 2010 г. «О Концепции развития уголовно-исполнительной системы Российской Федерации до 2020 года» (ред. от 23.09.2015) // С3 РФ. 2010. № 43. Ст. 5544.

2. Волов B.T., Тейван-Трейновский Я.С. Институт пробации как механизм социально-правового воздействия на личность с противоправным поведением // Вестник Самарского юридического института. 2013. № 3. С. 127-134.

3. Департамент тюрем при Министерстве юстиции Литовской Республики. [Электронный pecypc] URL: http://www.kaldep.lt/ru/departament-penitenciarnych-utchrezdenii/html электр. дан. Режим доступа: Компьютер. (дата обращения: 11.02.2016).

4. Канцелярия Канцлера юстиции Эстонии. [Электронный ресурс] URL: http://oiguskantsler.ee/ru/mesta-lisheniyasvobody-v-estonii электр. дан. Режим доступа: Компьютер. (дата обращения: 11.02.2016).

5. Тюремная служба Эстонии. [Электронный ресурс] URL: http://www.vangla.ee/ru электр. дан. Режим доступа: Компьютер. (дата обращения: 11.02.2016).

6. International Centre for Prison Studies. [Электронный ресурc] URL: http://www.prisonstudies.org/map/europe. Режим доступа: Компьютер. (дата обращения: 21.01.2016).

7. Иванова О.А. Об опыте реформирования пенитенциарной системы Латвии // Вестник Пермского института ФСИН России. 2014. № 1. С. 60-63.

8. European Commission. Justice. Daphne III. [Электронный ресурс] URL: http://ec.europa.eu/justice/criminal/programme/ daphne-programme/index_en.htm Режим доступа: Компьютер. (дата обращения: 14.02.2016).

9. STRONG - Capacity building of female prisoners with a history of violence and abuse - Resource Material - WIAD Scientific Institute of the Medical Association of German Doctors, Bonn, Germany. Project Manager: Dr Caren Weilandt, 2013. [Электронный ресурс] URL: http://philipus.de/daphne-strong.eu/DOCS/final_material/resource_material_UK.pdf. Режим доступа: Компьютер. (дата обращения: 14.02.2016).

10. STRONG - Capacity building for female prisoners with a history of violence and abuse. [Электронный pecypc] URL: $\mathrm{http} / /$ www.heuni.fi/en/index/researchareas/prison/strong-capacitybuildingforfemaleprisonerswithahistoryofviolenceandabuse. html (дата обращения: 14.02.2016).

11. MacDonald M. Women prisoners, mental health, violence and abuse // International Journal of Law and Psychiatry. 2013. V. 36. Iss. 3-4. P. 293-303.

12. Højdahl T., Magnus J.H., and Langeland E. «A bridge to change»: Experiences of participation in «VINN» - a motivational program for convicted women. A qualitative study // EuroVista. 2014. V. 3. No. 2. P. 81-96.

13. Иванова О.А. Опыт реформ пенитенциарной системы Эстонии // Вестник Пермского института ФСИН России. 2014. № 2. C. 29-32.

14. Kamenska A., Pūce I., and Laganovska K. Prison conditions in Latvia. European Prison Observatory. Detention conditions in the European Union. [Электронный ресурc] URL: http://www.prisonobservatory.org/upload/PrisonconditionsinLatvia.pdf (дата обращения: 17.02.2016).

15. Уткин B.A. Режим лишения свободы: между карой и безопасностью // Правовые проблемы укрепления российской государственности: сб. ст. Ч. 66 (изд. доп. и перераб.). Томск: Изд-во Том. ун-та, 2015. С. 53-55.

16. Centre for Crime and Justice Studies. Prison conditions in Latvia. [Электронный pecypc] URL: http://www.crimeand justice.org.uk/sites/crimeandjustice.org.uk/files/Prison\%20conditions\%20in\%20Latvia.pdf (дата обращения: 17.02.2016).

17. Kivimets K. and Uusküla A. HIV testing and counselling in Estonian prisons, 2012 to 2013: aims, processes and impacts // Eurosurveillance. 2014. V. 19. Iss. 47. P. 31-37.

18. European Centre for Disease Prevention and Control (ECDC) and World Health Organization Regional Office for Europe. HIV/AIDS Surveillance in Europe 2011. Stockholm: ECDC. 2012. [Электронный pecypc] URL: http://www.ecdc. europa.eu/en/publications/Publications/20121130-Annual-HIV-Surveillance-Report.pdf (дата обращения: 17.02.2016).

19. Abbing H.R. Prisoners right to healthcare, a European perspective // European Journal of Health Law. 2013. V. 20. Iss. 1. P. 5-19.

20. Zahars $V$. and Stivrenieks $M$. Security implementation facets: peculiarities of execution of the sentence of imprisonment in respect of convicted minors // Journal of Security and Sustainability Issues. 2015. V. 4. No. 3. P. 221-231.

21. Report to the Estonian Government on the visit to Estonia carried out by the European Committee for the Prevention of Torture and Inhuman or Degrading Treatment or Punishment (CPT) from 30 May to 6 June 2012. URL: http://www.cpt.coe.int/documents/est/2014-01-inf-eng.pdf (дата обращения: 19.02.2016).

22. Национальный доклад Государственного департамента США по правам человека 2013: Эстония (U.S. Department of State. Human Rights Report 2013: Estonia). [Электронный ресурc] URL: http://www.state.gov/documents/organization/ 220486.pdf (дата обращения: 19.02.2016).

23. Report to the Latvian Government on the visit to Latvia carried out by the European Committee for the Prevention of Torture and Inhuman or Degrading Treatment or Punishment (CPT) from 12 to 17 September 2013. [Электронный pecypc] URL: http://www.cpt.coe.int/documents/lva/2014-05-inf-eng.pdf (дата обращения: 20.02.2016).

24. Национальный доклад Государственного департамента США по правам человека 2014: Латвия (U.S. Department of State. Human Rights Report 2014: Latvia). [Электронный ресурc] URL: http://www.state.gov/documents/organization/ 236754.pdf (дата обращения: 20.02.2016).

25. Report to the Lithuanian Government on the visit to Lithuania carried out by the European Committee for the Prevention of Torture and Inhuman or Degrading Treatment or Punishment (CPT) from 27 November to 4 December 2012. [Электронный pecypc] URL: http://www.cpt.coe.int/documents/ltu/2014-18-inf-eng.pdf (дата обращения: 21.02.2016).

26. Национальный доклад Государственного департамента США по правам человека 2013: Литва (U.S. Department of State. Human Rights Report 2014: Lithuania). [Электронный ресурc] URL: http://www.state.gov/documents/organization/ 220511.pdf (дата обращения: 22.02.2016). 


\section{THE BALTIC TYPE OF THE EUROPEAN PENITENTIARY SYSTEMS}

Ugolovnaya yustitsiya - Russian Journal of Criminal Law, 2016, 2(8), 70-77. DOI 10.17223/23088451/8/11

Pavel V. Teplyashin, Siberian Law Institute of the Federal Drug Control Service of the Russian Federation (Krasnoyarsk, Russian Federation). E-mail: pavlushat@mail.ru

Keywords: Department of Penitentiary Institutions of Lithuania, model of convicts' accommodation, Nord-Balt project, Tallinn prison.

The article examines the Baltic type of penitentiary systems which acts as a site for the verification of the actively implemented Western models in the sphere of criminal sentence execution. It shows that this type is characterized by one of the highest prisoner rates among all types of European penitentiary systems, as well as by a large number of prisoners who are citizens of foreign states in the total number of convicts. The Baltic type is characterized by the departure from the Soviet model of the penitentiary system and by the implementation of predominantly Western European models. This is facilitated by the active cooperation of Latvia, Lithuania and Estonia with the authorities of penitentiary institutions of European countries and their participation in various international projects on the development of progressive forms and methods of treatment of prisoners (DAPHNE Strong, New Horizons, VINN, TACIS, etc.). Prison conditions in many correctional facilities are based on a prison cell model of prisoners' accommodation with elements of a progressive system. In some semi-open prisons, primarily in Latvia, convicts are accommodated in dormitories for 30-60 people. However, the Western model of the regime sets more requirements for ensuring the security of correctional facilities. The elements of the regime are not clearly detailed in legal acts, they are established and changed in the extrajudicial order, but under judicial control, the personality of the convicted person and its changes while serving the sentence are the criteria for changing the regime. Correctional institutions actively introduce individual programs for punishment execution, and use toxicological testing. There is quite a detailed legal regulation and vigorous work of penitentiary institutions on educational and resocialising work with underage convicts. The emergence and construction of private prisons and pre-trial detention centres in the three countries (especially in Latvia) is partly conditioned by the public trust in this institution, and is also predetermined by the solution of problems of state funding of penitentiary institutions through public-private economic partnership in this area. It is emphasised that reports of the representatives of the European Committee for the Prevention of Torture and Inhuman or Degrading Treatment or Punishment who visited the Baltic countries note violations of the rights of convicts or other shortcomings in the organization of the activities of prisons. A conclusion is drawn that the analysis of the Baltic penitentiary type allows to look more closely at the prospects of reforming the domestic penitentiary system.

\section{REFERENCES}

1. The Government of the Russian Federation. (2010) Rasporyazhenie Pravitel'stva Rossiyskoy Federatsii № 1772-r ot 14 oktyabrya 2010 goda «O Kontseptsii razvitiya ugolovno-ispolnitel'noy sistemy Rossiyskoy Federatsii do 2020 goda» (red. Ot 23.09.2015) [Order of the Government of the Russian Federation No. 1772-r of October 14, 2010 "On the Concept of the Development of the Penitentiary System of the Russian Federation until 2020" (as amended on September 23, 2015)]. Sobranie zakonodatel'stva Rossiyskoy Federatsii - Legislation Bulletin of the Russian Federation. 43. Art. 5544.

2. Volov, V.T. \& Teyvan-Treynovskiy, Ya.S. (2013) Institut probatsii kak mekhanizm sotsial'no-pravovogo vozdeystviya na lichnost' s protivopravnym povedeniem [Institute of probation as a mechanism of social and legal influence on the person with illegal behaviour]. Vestnik Samarskogo yuridicheskogo instituta - Bulletin of the Samara Law Institute. 3. pp. 127-134.

3. Ministry of Justice of the Republic of Lithuania. (n.d.) Departament tyurem pri Ministerstve yustitsii Litovskoy respubliki [Prison Department of the Ministry of Justice of the Republic of Lithuania]. [Online] Available from: http://www.kaldep.lt/ru/departament-penitenciarnych-utchrezdenii/html. (Accessed: 11th February 2016).

4. Chancellor of Justice of Estonia. (n.d.) Kantselyariya Kantslera yustitsii Estonii [Chancellery of the Chancellor of Justice of Estonia]. [Online] Available from: http://oiguskantsler.ee/ru/mesta-lisheniya-svobody-v-estonii. (Accessed: 11th February 2016).

5. Estonia. (n.d.) Tyuremnaya sluzhba Estonii [The Prison Service of Estonia]. [Online] Available from: http://www. vangla.ee/ru. (Accessed: 11th February 2016).

6. Prisonstudies.org. (n.d.) International Centre for Prison Studies. [Online] Available from: http://www.prisonstudies.org/ map/europe. (Accessed: 21st January 2016).

7. Ivanova, O.A. (2014) The issues of penal system reforming in Latvia. Vestnik Permskogo instituta FSIN Rossii - Vestnik of Perm Institute of the Federal Penal Service. 1. pp. 60-63. (In Russian).

8. European Commission. Justice. (2013) Daphne III. [Online] Available from: http://ec.europa.eu/justice/criminal/programme/ daphne-programme/index_en.htm. (Accessed: 14th February 2016).

9. WIAD - Scientific Institute of the Medical Association of German Doctors. (2013) STRONG - Capacity building of female prisoners with a history of violence and abuse. Bonn. [Online] Available from: http://philipus.de/daphnestrong.eu/DOCS/final_material/resource_material_UK.pdf. (Accessed: 14th February 2016).

10. WIAD - Scientific Institute of the Medical Association of German Doctors. (2013) STRONG - Capacity building for female prisoners with a history of violence and abuse. Bonn. [Online] Available from: http://www.heuni.fi/en/index/researchareas/ prison/strong-capacitybuildingforfemaleprisonerswithahistoryofviolenceandabuse.html. (Accessed: 14th February 2016).

11. MacDonald, M. (2013) Women prisoners, mental health, violence and abuse. International Journal of Law and Psychiatry. 36:3-4. pp. 293-303. DOI: 10.1016/j.ijlp.2013.04.014

12. Højdahl, T., Magnus, J.H. \& Langeland, E. (2014) «A bridge to change»: Experiences of participation in «VINN» - a motivational program for convicted women. A qualitative study. EuroVista. 3:2. pp. 81-96.

13. Ivanova, O.A. (2014) The experience of the reforms of penal system of Estonia. Vestnik Permskogo instituta FSIN Rossii Vestnik of Perm Institute of the Federal Penal Service. 2. pp. 29-32. (In Russian). 
14. Kamenska, A., Pūce, I. \& Laganovska, K. (2013) Prison conditions in Latvia. Rome: Antigone Edizioni. [Online] Available from: http://www.prisonobservatory.org/upload/PrisonconditionsinLatvia.pdf. (Accessed: 17th February 2016).

15. Utkin, V.A. (2015) Rezhim lisheniya svobody: mezhdu karoy i bezopasnost' [The regime of deprivation of liberty: between punishment and security]. In: Pravovye problemy ukrepleniya rossiyskoy gosudarstvennosti [Legal problems of strengthening Russian statehood]. Vol. 66. Tomsk: Tomsk State University. pp. 53-55.

16. Kamenska, A., Pūce, I. \& Laganovska, K. (2013) Prison conditions in Latvia. Rome: Antigone Edizioni. [Online] Available from: http://www.crimeandjustice.org.uk/sites/crimeandjustice.org.uk/files/Prison\%20conditions\%20in\%20Latvia.pdf. (Accessed: 17th February 2016).

17. Kivimets, K. \& Uusküla, A. (2014) HIV testing and counselling in Estonian prisons, 2012 to 2013: aims, processes and impacts. Eurosurveillance. 19:47. pp. 31-37.

18. European Centre for Disease Prevention and Control (ECDC) and World Health Organization Regional Office for Europe. (2012) HIV/AIDS Surveillance in Europe 2011. Stockholm: ECDC. 2012. [Online] Available from: http://www.ecdc. europa.eu/en/publications/Publications/20121130-Annual-HIV-Surveillance-Report.pdf. (Accessed: 17th February 2016).

19. Abbing, H.R. (2013) Prisoners right to healthcare, a European perspective. European Journal of Health Law. 20:1. pp. 5-19.

20. Zahars, V. \& Stivrenieks, M. (2015) Security implementation facets: peculiarities of execution of the sentence of imprisonment in respect of convicted minors. Journal of Security and Sustainability Issues. 4:3. pp. 221-231.

21. CPT. (2012) Report to the Estonian Government on the visit to Estonia carried out by the European Committee for the Prevention of Torture and Inhuman or Degrading Treatment or Punishment (CPT) from 30 May to 6 June 2012. [Online] Available from: http://www.cpt.coe.int/documents/est/2014-01-inf-eng.pdf. (Accessed: 19th February 2016).

22. U.S. Department of State. (2013) Human Rights Report 2013: Estonia. [Online] Available from: http://www.state.gov/ documents/organization/220486.pdf. (Accessed: 19th February 2016).

23. CPT. (2013) Report to the Latvian Government on the visit to Latvia carried out by the European Committee for the Prevention of Torture and Inhuman or Degrading Treatment or Punishment (CPT) from 12 to 17 September 2013. [Online] Available from: http://www.cpt.coe.int/documents/lva/2014-05-inf-eng.pdf. (Accessed: 20th February 2016).

24. U.S. Department of State. (2014) Human Rights Report 2014: Latvia. [Online] Available from: http://www.state.gov/ documents/organization/236754.pdf. (Accessed: 20th February 2016).

25. CPT. (2012) Report to the Lithuanian Government on the visit to Lithuania carried out by the European Committee for the Prevention of Torture and Inhuman or Degrading Treatment or Punishment (CPT) from 27 November to 4 December 2012. [Online] Available from: http://www.cpt.coe.int/documents/ltu/2014-18-inf-eng.pdf. (Accessed: 21st February 2016).

26. U.S. Department of State. (2014) Human Rights Report 2014: Lithuania. [Online] Available from: http://www.state.gov/ documents/organization/220511.pdf. (Accessed: 22nd February 2016). 